\title{
Future needs for ERCP: incidence of conditions leading to bile duct obstruction and requirements for diagnostic and therapeutic biliary procedures
}

\author{
M W L Gear, N A Dent, D G Colin-Jones, J H Lennard-Jones, J R T Colley
}

\begin{abstract}
Although the development of endoscopic methods of treatment for biliary obstruction has proceeded rapidly in recent years, endoscopic retrograde cholangiopancreatographic (ERCP) services are patchily distributed. A recent survey by the British Society of Gastroenterology has shown that almost half the district general hospitals questioned did not have a sphincterotomy service available locally. To assess the level of provision required, two investigations have been undertaken. Firstly, an epidemiological study of bile duct obstruction has been carried out in the South Western Region. Secondly, the actual surgical and endoscopic workload in treating obstructive jaundice has been analysed in two health districts. Using present incidence and treatment rates at least 50 ERCPs per 100000 of the population per year are estimated to be required in the future. Surgical treatment rates can be expected to fall as the number of therapeutic ERCPs increases. The implications of this estimate in equipment and staffing terms are discussed.
\end{abstract}

Obstruction of the bile duct produces severe and obvious clinical features that may include jaundice, pain, or fever. Thus, the patient will usually be referred for hospital investigation and treatment. The common causes of bile duct

obstruction are gall stones and tumours. Before the development of endoscopic methods of treatment for bile duct obstruction, most patients required operation - exploration of the duct and extraction of stones, resection, or bypass for tumours.

The development of endoscopic retrograde cholangiopancreatography (ERCP) was followed by sphincterotomy for gall stone in $1974^{1}$ and retrograde insertion of a biliary endoprosthesis for tumours (stenting) in 1981.2 Within the United Kingdom these methods are being used increasingly in some centres and not at all in others. A recent survey by the British Society of Gastroenterology has shown that almost half the district general hospitals questioned did not have a sphincterotomy service available locally. ${ }^{3}$ In the South Western Regional Health Authority, for example, excluding Bristol, only three of eight district general hospitals currently have an ERCP service.

At first, endoscopic sphincterotomy for duct stone was reserved for elderly and frail patients who had had previous biliary surgery. More recently, the indications have been widened to include older patients with gall bladder in situ, thus avoiding surgery altogether in many instances. ${ }^{46}$ Endoscopic stenting for malignant bile duct obstruction was reported after the percutaneous transhepatic methods had been used for some time. A recent trial from the Middlesex and the London Hospitals has sug-
Department of Surgery, Gloucestershire Royal Hospital, Gloucester $M$ W L Gear

Department of Epidemiology and Community Medicine Canynge Hall, Bristol NA Dent

J R T Colley

Department of Medicine, Queen Alexandra Hospital, Portsmouth

D G Colin-Jones

St Mark's Hospital, London

J E Lennard-Jones

Correspondence to:

$\operatorname{Mr} M$ W L Gear, Departmen of Surgery, Gloucestershire Royal Hospital, Glouceste GL1 3NN.

Accepted for publication 1 December 1989
TABLE I Origins and derivation of data (1981 population base)

\begin{tabular}{|c|c|c|c|}
\hline Disease & Incidence & Workload & Data problems \\
\hline $\begin{array}{l}\text { Cancer: } \\
\text { Duct/ampulla } \\
\text { Pancreas }\end{array}$ & $\begin{array}{l}\text { Cancer registration and death } \\
\text { certificates SWRHA (population } \\
3066000 \text { ) }\end{array}$ & $\begin{array}{l}\text { Theatre or endoscopy record. } \\
\text { Bypass or resection or stent (two } \\
\text { districts population } 812000 \text { ) }\end{array}$ & $\begin{array}{l}\text { Overestimate of potential workload } \\
\text { due to confusions in coding duct as } \\
\text { distinct from gall gladder, and } \\
\text { head of pancreas as distinct from } \\
\text { body/tail. Some bypass surgery } \\
\text { done for non-malignant conditions } \\
\text { (about } 1 \text { in } 10 \text { in HAA) }\end{array}$ \\
\hline Duct stones & $\begin{array}{l}\text { HAA exluding readmissions } \\
\text { within } 3 \text { months }(3066000)\end{array}$ & $\begin{array}{l}\text { Exploration of CBD or endoscopic } \\
\text { sphincterotomy. Theatre or } \\
\text { endoscopy record }(8120000)\end{array}$ & $\begin{array}{l}\text { Under-recording of subsidiary } \\
\text { diagnosis in HAA. Overestimate } \\
\text { of cases due to uncertain matching } \\
\text { of readmissions }\end{array}$ \\
\hline $\begin{array}{l}\text { Other duct pathology, } \\
\text { obstructive } \\
\text { jaundice }\end{array}$ & $\begin{array}{l}\text { HAA excluding readmissions } \\
\text { within } 3 \text { months }(3066000)\end{array}$ & $\begin{array}{l}\text { Any of the key workload categories } \\
\text { associated with other diagnoses }\end{array}$ & $\begin{array}{l}\text { Diagnostic categories not adequate } \\
\text { or not adequately recorded in } \\
\text { HAA. Incidence is procedure } \\
\text { (workload) led and includes } \\
\text { apparently negative cases, eg } \\
\text { ECBD }\end{array}$ \\
\hline
\end{tabular}

Relevant codes: ICD 9 and operations:

Stones ICD 574.X; duct stones ICD 574. 3,4,5; biliary tumours ICD 156; pancreatic tumours ICD 157; exploration of common bile duct 510; choledocholithotomy 511; Bypass operations 513,523,524; pancreatectomy 531; partial pancreatectomy 532; ERCP 539.

Office of Population Census and Surveys surgical codes 4th revision were brought into use in Gloucester in 1988. These have resulted in closer agreement between theatre registers and HAA

HAA = Hospital Activity Analysis; $\mathrm{CBD}=$ common bile duct; $\mathrm{ECBD}=$ exploration of common bile duct $\mathbf{E R C P}=$ endoscopic retrograde cholangiopancreatography; SWRHA=South Western Regional Health Authority. 
TABLE II 1981 Populations by age (years), numbers in thousands (\%)

\begin{tabular}{|c|c|c|c|c|c|}
\hline & $\leqslant 54$ & $\leqslant 55$ & $\leqslant 65$ & $\geqslant 75$ & Total \\
\hline $\begin{array}{l}\text { Gloucester and Portsmouth } \\
\text { Health Districts } \\
\text { England }\end{array}$ & $\begin{array}{c}602 \cdot 6 \\
(74 \cdot 2) \\
34393 \cdot 3 \\
(73 \cdot 5)\end{array}$ & $\begin{array}{c}90 \cdot 2 \\
(11 \cdot 1) \\
5261 \cdot 5 \\
(11 \cdot 2)\end{array}$ & $\begin{array}{c}72 \cdot 1 \\
(8 \cdot 9) \\
4372 \cdot 3 \\
(9 \cdot 3)\end{array}$ & $\begin{array}{r}47 \cdot 0 \\
(5 \cdot 8) \\
2758 \cdot 7 \\
(5 \cdot 9)\end{array}$ & $\begin{array}{c}811.9 \\
(100 \cdot 0) \\
46785 \cdot 8 \\
(100 \cdot 0)\end{array}$ \\
\hline
\end{tabular}

Source - Office of Population Census and Surveys, population estimates. ${ }^{13}$

gested that the endoscopic method is safer and more successful in relieving jaundice than the percutaneous route.

Surgical resection of tumours causing obstruction of the bile duct is only possible in up to $10-20 \%$ of patients and even simple palliative bypass procedures are associated with substantial morbidity and a mortality of up to $30 \% .{ }^{8}$ Furthermore, patients with tumours are often elderly and considered unfit for surgery. Thus, nonoperative methods of palliation in these patients provides an attractive alternative treatment. ${ }^{9}$

The advent of endoscopic methods for investigating and treating bile duct obstruction has considerable implications for hospitals throughout the country. They provide a potential saving in operating theatre requirements, but a need for extra endoscopic and radiological facilities. In addition, skilled and trained medical and nursing staff are required.

This paper estimates the potential endoscopic workload for treatment of obstructive jaundice in two ways. Firstly, the incidence of conditions leading to bile duct obstruction is assessed and secondly the actual surgical and endoscopic workload in two health districts has been determined. Additionally, the effects of endoscopic techniques on surgical practice have been analysed in these districts. From these data, an attempt is made to predict future requirements for diagnostic and therapeutic ERCP facilities for each 100000 of the population.

\section{Methods}

The methods used in this study are set out and discussed in the Appendix. The data sources, together with brief details of the problems encountered, the population sizes, and age structure are summarised in Tables I and II.

\section{Results}

REGIONAL INCIDENCE OF CONDITIONS LEADING TO BILE DUCT OBSTRUCTION

Tumours. The incidence of carcinoma of the pancreas and biliary system in the South Western Region has been rising slowly over the 10 years from 1976 (Fig 1). In recent years approximately 480 new patients have presented each year, equivalent to 16 in a population of 100000 . Neoplasms of the bile ducts or gall bladder account for about one in six of the cases (Table III). A striking feature of the age distribution is that $76.8 \%$ ( 1869 of 2433 ) of the whole group are over the age of 65 years, and indeed $42.9 \%$ (1045 of 2433) are 75 years or older.

Not all patients with carcinoma of the pancreas will have obstruction of the bile duct. Some assessment of the minimum numbers receiving

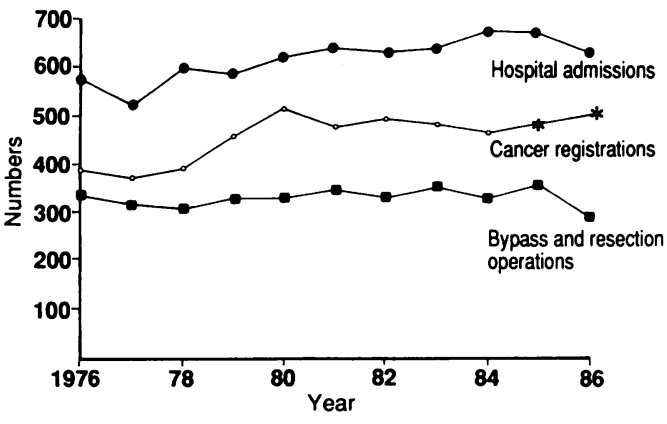

Figure 1: Annual hospital admissions and operations compared with cancer incidence (pancreas and bile duct) for South Western Regional Health Authority between 1976 and 1986.

${ }^{\star}$ Estimate based on death certificates.

surgical treatment can be derived from the data on treatment episodes and admissions (Fig 1). Hospital admission rates for cancers exceed the annual incidence because a proportion of patients are admitted more than once, despite the fact that the two year survival rate is only about $4 \%$ for cancer of the pancreas. ${ }^{10}$ Thus there are approximately 650 hospital admissions per year for these cancers in this region. The number of operations, however, is about half the admission rate, at approximately 300 per year - that is 10 per 100000 of the population. This is partly because not all carcinomas of the pancreas affect the bile duct and partly because some patients are so old and frail that surgery is not possible.

Bile duct stones. The hospital admission rate for all gall stones in the period 1979-86 in this region was approximately 100 per 100000 . Duct stones were present in about one in eight patients giving an approximate admission rate of 13 per 100000 (Table IV). The proportion of episodes in which duct stones were mentioned increased from $9 \%$ below the age of 64 years to $19 \%$ in the $65+$ age group. Fifty eight per cent of all cases of duct stones (1882 of 3253) occurred in patients over the age of 65 , and $29 \%$ were over 75 years.

For reasons discussed in the Appendix (mainly problems in ascertainment and coding) these figures are likely to be an underestimate of the true incidence of episodes involving duct stones. If the proportions of missed diagnostic codes are similar to those found in the district studies for exploration of the common bile duct operations (Fig 2) the true figure may be about $20 \%$ higher - say 16 per 100000 .

Ninety per cent of all readmissions in patients with duct stones which were identified in Hospital Activity Analysis (HAA) within two years of a first admission occurred within three months of that admission. Taking the view that

TABLE III Numbers of patients with carcinoma of the pancreas and biliary system by age (yrs) registered in the five pancreas and bitiod 1979-83 in the South Western Regional Health Authority (population 3066000 )

\begin{tabular}{llll}
\hline & \multicolumn{4}{c}{$N o($ rates $/ 100000$ per year) } \\
\cline { 2 - 4 } Tumour (ICD9) & $\leqslant 65$ & $\geqslant 65$ & All ages \\
\hline Gall bladder and bile ducts & & & \\
$\quad(156)$ & $100(0 \cdot 8)$ & $312(11 \cdot 6)$ & $412(2 \cdot 7)$ \\
Pancreas (157) & $464(3 \cdot 7)$ & $1557(57 \cdot 8)$ & $2021(13 \cdot 2)$ \\
Totals & $564(4 \cdot 5)$ & $1869(69 \cdot 4)$ & $2433(15 \cdot 9)$ \\
\hline
\end{tabular}

Source - Cancer Registry. 
TABLE IV Hospital admission rates for biliary stones, by age (yrs), between 1979 and 1986 in the South Western Regional Health Authority (population 3066000 )

\begin{tabular}{|c|c|c|c|}
\hline & \multicolumn{3}{|c|}{ No (rates $/ 100000$ per year) } \\
\hline & $\leqslant 64$ & $\geqslant 65$ & All ages \\
\hline $\begin{array}{l}\text { All stones } \\
\text { Duct stones }\end{array}$ & $\begin{array}{c}15519(76 \cdot 8) \\
1371(6 \cdot 8)\end{array}$ & $\begin{array}{l}9907(229.9) \\
1882(43.7)\end{array}$ & $\begin{array}{r}25426(103 \cdot 7) \\
3253(13 \cdot 3)^{\star}\end{array}$ \\
\hline $\begin{array}{l}\text { Duct stones as \% } \\
\text { of all stones }\end{array}$ & $8 \cdot 8$ & $19 \cdot 0$ & $12 \cdot 8$ \\
\hline
\end{tabular}

Source - Hospital Activity Analysis episodes

$\star$ Clinical episodes arising in 2673 patients (see text).

such close readmissions are part of the same episode leads to the conclusion that 2673 patients (11/100000 per year) experienced 3253 admissions in an eight year period.

WORKLOAD IN THE TREATMENT OF BILE DUCT OBSTRUCTION IN THE TWO HEALTH DISTRICTS Thus far data from the South Western Regional Health Authority as a whole have been presented in terms of incidence rates.

This section presents a circumscribed study from 1977 to 1988 of treatment rates in two health districts - Gloucester and Portsmouth whose combined population at the mid-point was just over 812000 , with an age structure which mirrors closely that of England and Wales (Table II). Principal features of the treatment rates in this combined population are summarised for the two five year periods 1977-81 and 1982-6, and the trends for the two ERCP centres are updated separately to 1988 .

Malignant obstruction. The rates for excision and bypass surgery or palliative insertion of biliary stents averaged 8 per 100000 , or 37 per 100000 over 65 (Table V). Stenting was not practised before 1981 but its introduction in the second five year period increased the total workload by $13 \%$.

Duct stone and associated conditions. The treatment rate in the two districts was about $19 / 100000$ population per year in the first half of the study period when ERCPs accounted for one in nine treatments (Table VI). Between 1981 and 1986, with increasing use of ERCP, which accounted for about one third of all treatments, the operation rate for exploration of the common bile duct declined. The total treatment rate for duct stones and their associated complications was unchanged at 155 cases per year (19 per

TABLE V Bypass operations and pancreatectomies (ops) and stents (stents) by age (yrs) and period for Gloucester and Portsmouth Health Districts combined

\begin{tabular}{|c|c|c|c|c|c|c|c|}
\hline & \multicolumn{2}{|l|}{$<64$} & \multicolumn{2}{|l|}{$\geqslant 65$} & \multicolumn{2}{|l|}{ All ages } & \multirow[b]{2}{*}{ Total } \\
\hline & Ops & Stents & Ops & Stents & Ops & Stents & \\
\hline $\begin{array}{l}\text { No: } \\
\quad 1977-81 \\
1982-6 \\
\text { Total 1977-86 } \\
\text { All treatments (\%) }\end{array}$ & $\begin{array}{l}93 \\
98 \\
191 \\
205(32)\end{array}$ & $\begin{array}{r}0 \\
14 \\
14\end{array}$ & $\begin{array}{l}202 \\
182 \\
384 \\
422(68)\end{array}$ & $\begin{array}{r}0 \\
58 \\
58\end{array}$ & $\begin{array}{l}295 \\
280 \\
575 \\
647(100)\end{array}$ & $\begin{array}{r}0 \\
72 \\
72\end{array}$ & $\begin{array}{l}295 \\
352 \\
647\end{array}$ \\
\hline $\begin{array}{l}\text { Rates (all treatments) } / 1000 \\
1977-81 \\
1982-6 \\
\text { Total } 1977-86\end{array}$ & $\begin{array}{l}000 \text { per y } \\
2 \cdot 8 \\
3 \cdot 1 \\
3 \cdot 0\end{array}$ & & $\begin{array}{l}34 \cdot 0 \\
40 \cdot 2 \\
37 \cdot 1\end{array}$ & & $\begin{array}{l}7 \cdot 4 \\
8 \cdot 5 \\
8 \cdot 0\end{array}$ & & \\
\hline $\begin{array}{l}\text { Stents as \% of all treatment } \\
1977-81 \\
1982-6\end{array}$ & $\begin{array}{l}0 \\
12 \cdot 5\end{array}$ & & $\begin{array}{c}0 \\
24 \cdot 2\end{array}$ & & $\begin{array}{c}0 \\
20 \cdot 4\end{array}$ & & \\
\hline
\end{tabular}

Source - local theatre and endoscopy records.

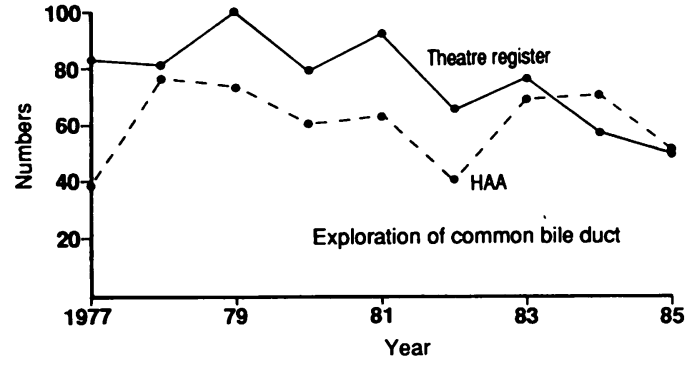

Figure 2: Comparison of theatre register and Hospital Activity Analysis (HAA) for exploration of common bile duct (Gloucester).

$100000)$. This higher rate, compared with that for duct stone incidence (noted earlier as 11 per 100000 ) is partly due to repeat treatment episodes, to the treatment of complications without mention of duct stones, and to diagnostic under-reporting in HAA. The higher rate does, however, reflect the actual workload in the treatment of pathology arising from duct stones. Table VI also shows that the elderly benefited most from the newer methods of treatment for duct stones in the second period compared with the first.

\section{COMBINED WORKLOAD FOR MALIGNANT}

\section{OBSTRUCTION AND BILE DUCT STONES}

Overall treatment rates by age for the 10 years between 1977 and 1986 are set out in Table VII, producing an average of $27 \cdot 0$ per 100000 for all treatments carried out in past years. Within this total, however, therapeutic endoscopic biliary procedures for Gloucester residents have risen from $12 \%$ of 91 procedures in 1981 to $50 \%$ of 99 in 1986 and $72 \%$ of 126 in 1988 (Fig 3). Similar trends are seen in Portsmouth (Fig 4) where the proportion of patients treated by endoscopic methods has grown from $22 \%$ to $55 \%$ over the same period. In practice these changes have affected most those over 65 . In $1988,50 \%$ more patients over this age were treated compared with the average of the previous decade, whereas rates for patients below 65 years were unchanged (Tables VII and VIII).

\section{Discussion and conclusions}

Cancer registries have for many years provided data on the incidence of malignant conditions affecting the biliary tract. There has, however, been an almost complete absence of data on the incidence of stones in the common bile duct. Our study attempts to provide data and to link the incidence of common bile duct stones to overall treatment rates, whether by surgical or endoscopic methods. Endoscopic treatment of common bile duct stones becamë stablished in the late 1970s and of malignant obstructive jaundice in the 1980s. As with any new technique, the ability to undertake the method is spread unevenly over the country. Until this study there has been no estimate of the likely workload to be expected using the new techniques, and this is needed to allow rational planning with regard to manpower, training, and resources.

In estimating future requirements for a new 
TABLE VI Exploration of common bile duct (ECBD) and therapeutic endoscopic retrograde cholangiopancreatography (ERCP) for stone by age (yrs) and period in Gloucester and Portsmouth Health Districts combined

\begin{tabular}{|c|c|c|c|c|c|c|c|}
\hline & \multicolumn{2}{|l|}{$<64$} & \multicolumn{2}{|l|}{$\geqslant 65$} & \multicolumn{2}{|l|}{ All ages } & \multirow[b]{2}{*}{ Total } \\
\hline & $E C B D$ & $E R C P$ & $E C B D$ & $E R C P$ & $E C B D$ & $E R C P$ & \\
\hline $\begin{array}{l}\text { No: } \\
\quad 1977-81 \\
1982-6 \\
\text { Total 1977-86 } \\
\text { All treatments (\%) }\end{array}$ & $\begin{array}{l}360 \\
273 \\
633 \\
739(48)\end{array}$ & $\begin{array}{r}33 \\
73 \\
106\end{array}$ & $\begin{array}{l}303 \\
227 \\
530 \\
807(52)\end{array}$ & $\begin{array}{r}73 \\
204 \\
277\end{array}$ & $\begin{array}{l}663 \\
500 \\
1163 \\
1546(100)\end{array}$ & $\begin{array}{l}106 \\
277 \\
383\end{array}$ & $\begin{array}{r}769 \\
777 \\
1546\end{array}$ \\
\hline $\begin{array}{l}\text { Rates (all treatmen } \\
1977-81 \\
1982-6 \\
\text { Total } 1977-86\end{array}$ & $\begin{array}{c}000 \text { per } y \\
11 \cdot 3 \\
10 \cdot 0 \\
10 \cdot 7\end{array}$ & ear: & $\begin{array}{l}63 \cdot 2 \\
72 \cdot 4 \\
67 \cdot 8\end{array}$ & & $\begin{array}{l}18.9 \\
19 \cdot 1 \\
19 \cdot 0\end{array}$ & & \\
\hline $\begin{array}{c}\text { Therapeutic ERCP } \\
1977-81 \\
1982-6\end{array}$ & $\begin{array}{c}\text { of all treat } \\
8 \cdot 4 \\
21 \cdot 1\end{array}$ & nents: & $\begin{array}{l}19 \cdot 4 \\
47 \cdot 3\end{array}$ & & $\begin{array}{l}13.8 \\
35.6\end{array}$ & & \\
\hline
\end{tabular}

Source - local theatre and endoscopy records.

technique such as therapeutic ERCP there are several major problems. Firstly, there are difficulties in analysing routine data, in part due to failure to record some diagnoses and treatments completely (see Appendix). Secondly, with rapidly changing technologies such as the advent of lithotripsy, the extent to which therapeutic ERCP is used in the years ahead must be in part speculation. A recent leading report, however, has recommended ERCP as the best means of treatment for most patients with bile duct obstruction. ${ }^{11}$ In the future more patients are likely to be treated overall, as ERCP is used increasingly for those who would be refused surgery. There are already signs that this is occurring in both Gloucester and Portsmouth (Figs 3 and 4).

The present situation in the management of bile duct obstruction is unsatisfactory in that ERCP is available in some district hospitals and not in others ${ }^{3}$ despite evidence that ERCP, particularly for older patients, is associated with a shorter hospital stay and lower complication rate. ${ }^{9}$

Using regional data, the incidence rate for cancer of the pancreas and bile ducts is 16 per 100000 . There are also a small number of patients who have biliary obstruction due to other secondary tumours. Hitherto, at least one third of these patients has been unsuitable for any surgical treatment. It seems reasonable to estimate that in future more patients will be suitable for endoscopic palliation and that the proportion treatable may rise to about 12 per 100000 , eight being treated endoscopically and the remainder being treated surgically or being unsuitable for either mode of treatment.

Also from regional data, the minimum

TABLE VII Overall treatment rates for malignant obstruction and bile duct stones by age (yrs). All cases for the 10 years 1977-86 in Gloucester and Portsmouth Health Districts combined (mid-population 812000)

\begin{tabular}{llll}
\hline & \multicolumn{3}{c}{$N o$ (rates/100000 per year) } \\
\cline { 2 - 4 } & $\leqslant 64$ & $\geqslant 65$ & All ages \\
\hline $\begin{array}{l}\text { Exploration of CBD or } \\
\text { sphincterotomy for stone }\end{array}$ & $739(10 \cdot 7)$ & $807(67 \cdot 8)$ & $1546(19 \cdot 0)$ \\
$\begin{array}{l}\text { Bypass, pancreatectomy, or } \\
\text { stents }\end{array}$ & $205(3 \cdot 0)$ & $442(37 \cdot 1)$ & $647(8 \cdot 0)$ \\
All cases & $944(13 \cdot 7)$ & $1249(104 \cdot 9)$ & $2193(27 \cdot 0)$ \\
\hline
\end{tabular}

Source - local theatre and endoscopy records. $\mathrm{CBD}=$ common bile duct.

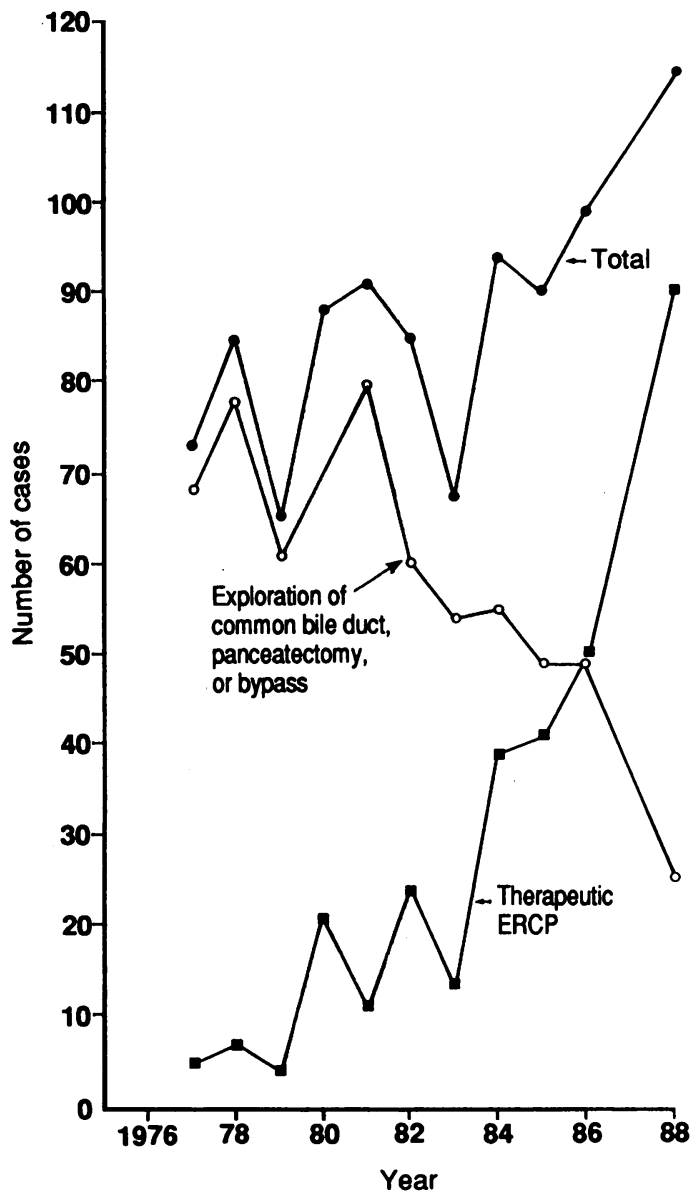

Figure 3: Annual workload for surgical and endoscopic biliary procedures in Gloucester 1977-88.

$E R C P=$ endoscopic retrograde cholangiopancreatography.

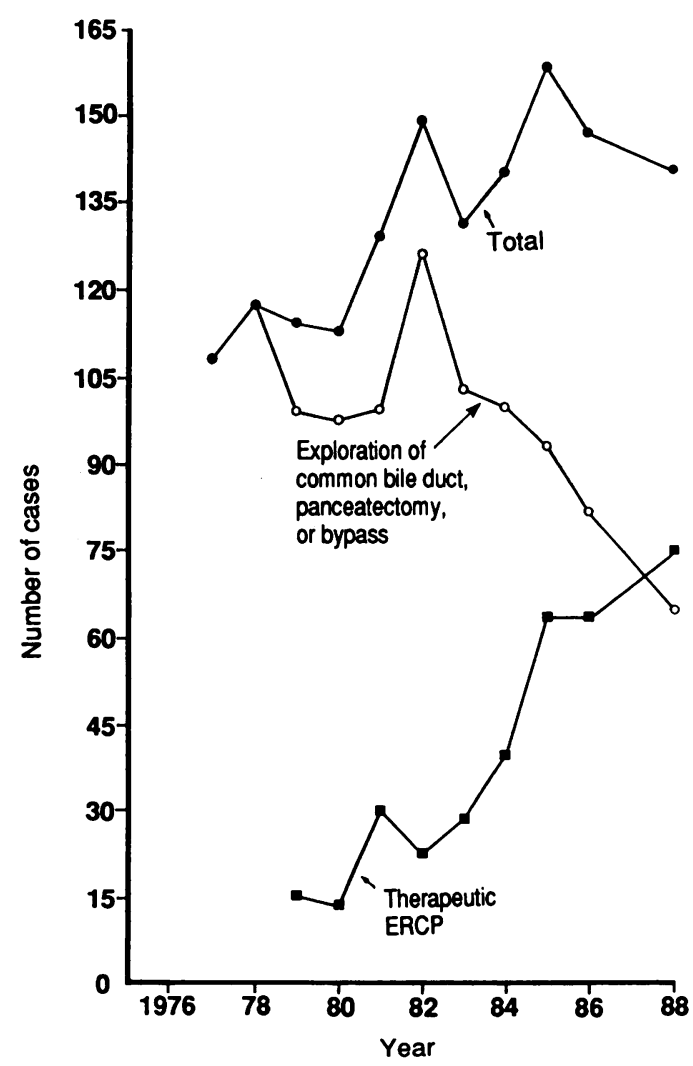

Figure 4: Annual workload for surgical and endoscopic biliary procedures in Portsmouth 1977-88.

$E R C P=$ endoscopic retrograde cholangiopancreatography. 
TABLE VIII Overall treatment rates by age for all cases for 1988 in Gloucester and Portsmouth Health Districts combined (population 841 500)

\begin{tabular}{llcc}
\hline & \multicolumn{3}{l}{$N o$ (rates/100000 per year) } \\
\cline { 2 - 4 } & $\leqslant 64$ & $\geqslant 65$ & All ages \\
\hline $\begin{array}{l}\text { Exploration of CBD or } \\
\text { sphincterotomy for stone }\end{array}$ & $62(8 \cdot 7)$ & $117(42 \cdot 1)$ & $179(21 \cdot 3)$ \\
$\begin{array}{l}\text { Bypass, pancreatectomy, or } \\
\text { stents }\end{array}$ & $16(2 \cdot 2)$ & $61(48 \cdot 0)$ & $77(9 \cdot 2)$ \\
\begin{tabular}{l} 
All cases \\
\hline
\end{tabular} & $78(10 \cdot 9)$ & $178(140 \cdot 2)$ & $256(30 \cdot 4)$ \\
\hline
\end{tabular}

Source - local theatre and endoscopy records. $\mathrm{CBD}=$ common bile duct.

incidence rate (including readmissions) for duct stones is 13 per 100000 . Our district studies lead us to believe that this is an underestimate and should be of the order of at least 16 per 100000 because of the data problems discussed in the Appendix. Therefore the combined incidence rates for treatable conditions would be 28 per 100000 .

This estimate is supported by the analysis of treatment rates in two health districts based on 10 years' data which showed a treatment rate of $27 \cdot 0$ per 100000 .

The most recent data for Gloucester residents show that the proportion of interventions for bile duct obstruction which are carried out endoscopically has increased from $50 \%$ to $80 \%$ in the last two years. Similar trends are evident in Portsmouth. About one in five treatments are repeat procedures - a readmission rate similar to that described above for surgery. First endoscopic treatments in 1988 occurred at a rate of 23 per 100000 but repeat treatments raised this figure to 30 per 100000 .

Although there will always be some who



Figure 5: Total endoscopic retrograde cholangiopancreatography (ERCP) workload-diagnostic and therapeutic - for Gloucester 1973-88. require surgical treatment, for example younger patients with malignancy or those with empyema of the gall bladder and duct stones, there is little evidence yet that the transition from surgery to endoscopic management is complete. Thus, up to 33 to 35 endoscopic treatments per 100000 may well be required. Although some of these may be at the expense of diagnostic ERCP, the latter has remained steady at 15 per 100000 in Gloucester in the past 10 years while endoscopic treatments have risen (Fig 5). Consequently, new and repeat treatments and diagnostic ERCPs together equate to an eventual rate of around 50 per 100000 . To take some account of differing age structures in other districts, an alternative way of expressing needs might be in terms of those aged over 65 . Based on treatment rates of 140 per 100000 (Table V) future requirements, including diagnostic ERCP, will be in excess of 200 per 100000 over 65 .

If the population served is around 500000 (that is, two adjoining districts) then 250 ERCPs will be required annually - equivalent to two sessions each of approximately three to four patients most weeks. Ideally these would be provided by two consultants, a physician, and a surgeon, thus allowing cover for holidays and for joint management of acutely ill patients. Radiological support, including ultrasound and interventional techniques, are also required. The advent of the combined percutaneous and endoscopic stenting technique, which increases the endoscopic success rate in our experience and in that of others ${ }^{12}$ to close to $100 \%$, reinforces the need for specialist radiological skills. Teaching hospitals, with referral from several health districts as well as research commitments, may require more sessions than is suggested by their nominal catchment area.

ERCP procedures are technically difficult, with a long 'learning curve.' In the early stages there is no substitute for a substantial period of apprenticeship in an established unit, often a teaching centre, as well as attendance at training courses. $^{3}$ For a small district it is doubtful whether an ERCP service can be justified. The best solution would seem to be for adjoining districts to cooperate in setting up a combined unit so that sufficient staff, expertise, and equipment is acquired in both the endoscopy and radiology departments. Alternatively, districts close enough to a regional centre may refer patients there.

\section{Appendix}

DATA COLLECTION

Introduction. The interpretation of morbidity rates based on routine National Health Service statistics is hampered by many difficulties. Both data collection and data analysis may be selective. Hospital readmission and recurrence may complicate attempts to measure disease incidence.

For patients with cancer, the National Registration Scheme provides a simple single record of incidence. Individuals with cancer of the pancreas or biliary tract have a short life expectancy, ${ }^{10}$ and there is thus a close correlation 


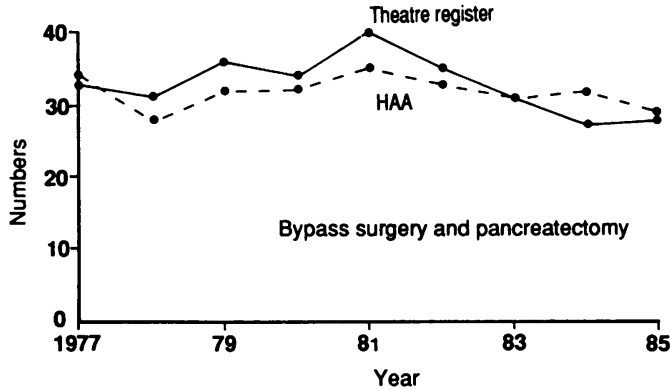

Figure 6: Comparison of theatre register and Hospital Activity Analysis for biliary bypass surgery and pancreatectomy (Gloucester).

between numbers of registrations and numbers of deaths, leading,to confidence in the estimates of incidence for these cancers.

For patients with stones in the biliary tract, it is difficult to obtain an accurate figure for incidence, as there is no register or longitudinal record available. Apart from any special local record systems which may have been developed, statistics can only be provided from Hospital Activity Analysis (HAA) and kindred systems for example, Hospital In-Patient Enquiry (HIPE) which describes hospital In-Patient episodes and which does not readily distinguish between separate patients, readmissions, and transfers. All these factors tend to inflate simple estimates of incidence based on these sources.

Procedures laid down for data extraction and coding also affect results in the HAA. For example, the codes of the ICD 9 revision attempt to distinguish stones in the bile duct (codes $574 \cdot 3-574 \cdot 5$ ) from calculus in the gall bladder. However, when coding, it is likely that in some instances the stone in the duct is overlooked or specificity is lost through precedence being given to the stone in the gall bladder. Similarly, there may be some failures to code such apparently subsidiary operations as choledocholithotomy (code 511) or exploration of the common bile duct (510), where cholecystectomy is more immediately perceived and coded (code 522). The combined effect of these factors has distorted the picture provided by national statistics in the past, particularly in the apparent ratio between types of operations performed. ${ }^{13}$ Earliest impressions of the fourth revision of the Office of Population Census and Surveys surgical codes, which were brought into use in Gloucester in 1988, suggest that many of these coding difficulties may not arise in the future.

Method. A preliminary and rigorous analysis of the regional HAA file to include subsidiary HAA diagnosis and operations was carried out. Special searches of theatre registers in two districts showed that exploration of the common bile duct appeared less frequently in HAA than in theatre registers because of negative findings on exploration (Fig 2). Choledocholithotomy was mentioned more often in HAA especially where calculus in the duct appears as one of the coded diagnoses. In contrast, there was close correlation between theatre register and HAA data for biliary bypass surgery (Fig 6).

Thus, for the purpose of our study, data for therapeutic events for 1977-88 were extracted by one of us (NAD) from local theatre and endo- scopy records in the Gloucester and Portsmouth health districts. Additionally, in Portsmouth, a computer system operated in the division of surgery provided further information for one hospital from 1983-8, which confirmed the findings from some theatre registers.

As theatre registers do not provide a record of diagnosis, disease incidence is derived from HAA and the National Registration Scheme throughout and is based on a whole region. Because the number of patients involved tends to be overestimated in HAA due to readmission or hospital transfer, an attempt was made to establish incidence by matching successive HAA admissions with any mention of duct stone, within district, by unit number, date of birth, sex, and diagnosis.

In determining age specific rates, data for several years were compared and combined for the two study districts and related to relevant Office of Population Census and Surveys denominators. ${ }^{14}$ This provided a population of approximately 812000 in 1981 , the midpoint of the study, with a broad age composition similar to that for England as a whole (Table II).

The data sources, together with brief details of the problems encountered, broad population numbers, and the ICD 9 diagnostic codes used in this study, are set out in Table I.

This study was undertaken on behalf of the Clinical Services Committee of the British Society of Gastroenterology.

We are most grateful to the Gloucester District Health Authority and the research fund of the British Society of Gastroenterology for providing finance for this project. We are grateful to the surgeons in Gloucester and Portsmouth for access to the theatre records and to $\mathrm{Mr}$ W G Prout for the use of the Portsmouth computer system. We also thank Mr R Moody of the Regional Health Authority for assistance with the Hospital Activity Analysis system. We thank Mrs Gillian Kellett for all her hard work in the preparation of the paper and Miss Jane Price for the diagrams.

1 Classen M, Demling L. Endoscopische Sphincterotomie der Papilla Vater. Disch Med Wochenschr 1974; 99: 496-7.

2 Huibregtse K, Havercamp HJ, Tytgat GN. Trans-papillary positioning of a large bore $3.2 \mathrm{~mm}$ biliary endoprosthesis. Endoscopy 1981; 13: 217-9.

3 Report of a working party of the British Society of Gastroenterology. The staffing of endoscopy units. British Society of Gastroenterology, 3 St Andrew's Place, London NW1 4LB: 1987

4 Neoptolemos JP, London NJ, James D, Carr-Locke DL, Bailey IA, Fossard DP. Controlled trial of urgent endoscopic retrograde cholangiopancreatography and endoscopic sphincterotomy versus conservative treatment for acute pancreatitis due to gall-stones. Lancet 1988; 2 : 979-83.

5 Neoptolemos JP, Carr-Locke DL, Fossard DP. Prospective randomized study of pre-operative endoscopic sphincterorandomized study of pre-operative endoscopic sphincterotomy versus surgery alone

6 Cotton PB. Endoscopic management of bile duct stones: (apples and oranges). Gut 1984; 25: 587-97.

7 Speer AG, Cotton PB, Russell RCG, et al. Randomized trial of endoscopic versus percutaneous stent insertion in malignant obstructive jaundice. Lancet 1987; 2: 57-62.

8 Little JM. A prospective evaluation of computerized estimates of risk in the management of obstructive jaundice. Surgery 1987; 102: 473-6.

9 Shepherd HA, Royle G, Ross APR, Diba A, Arthur M, ColinJones DG. Endoscopic biliary endoprosthesis in the palliation of malignant obstruction of the distal common bile duct: a randomised trial. Brf Surg 1988; 75: 1166-8.

10 South West Regional Health Authority. Report of the Cancer Registry. SWRHA Bristol, 1987.

11 Summerfield JA. Biliary obstruction is best managed by endoscopists. Gut 1988; 29: 741-5.

12 Robertson DAF, Ayres R, Hacking CN, Shepherd H, Birch S, Wright $R$. Experience with a combined percutaneous endoWright $R$. Experience with a combined percutaneous endoscopic approach to stent inser

13 Office of Population Census and Surveys. Hospital inpatient enquiry main tables. Series $M B 4$, No 21, 23, 25, 27. London: HMSO, 1982-5.

14 Office of Population Census and Surveys. Population estimates. Series PPI No 4, No. 6, No 8. London: HMSO, 1979, 1981, 1983. 